Cancer chemoprevention is defined as the application of natural or synthetic agents to suppress or reverse cancer development and progression. In this field especially diet derived compounds have recently attracted researchers' attention as potential therapeutics generally exerting low toxicity compared with regular drugs. This review presents a survey of recent findings concerning the most promising dietary chemopreventive agents such as green tea polyphenols (i.e. catechins), longchain polyunsaturated fatty acids, carotenoids, glucosinolates/isothiocyanates, vitamins (i.e. vitamin D and folate) and minerals (i.e. calcium and selenium). Molecular targets involved in intrinsic pathways affected by these natural compounds are also shortly discussed.

Key words: cancer chemoprevention, green tea polyphenols, polyunsaturated fatty acids, glucosinolates, carotenoids.

\section{Dietary derived compounds in cancer chemoprevention}

\author{
Ewa Langner ${ }^{1}$, Wojciech Rzeski ${ }^{12}$
}

1Department of Medical Biology, Institute of Agricultural Medicine, Lublin, Poland 2Department of Virology and Immunology, Institute of Microbiology and Biotechnology, Maria Curie-Skłodowska University, Lublin, Poland

\section{Introduction}

As there is overall agreement that preventing disease is more desirable than curing, a multitude of potential chemopreventive compounds are under investigation. The term chemoprevention, first introduced by Sporn, means inhibiting, suppressing or reversing cancer development and progression with the use of natural or synthetic agents [1]. Chemopreventives should be characterized by low toxicity comparable with therapeutic drugs and a possibility to be taken orally [2, 3]. Nowadays, a new definition of chemoprevention can be stated and it can be described as the use of compounds suppressing or reversing the molecular pathways leading to cancer development and metastasis $[4,5]$.

Different dietary patterns in distinct countries are related to higher or lower incidences of cancer development in these ethnic groups, which confirms an inverse association between food borne preventive compounds and carcinogenesis. Lower incidence of breast, prostate and gastrointestinal tract cancer were always observed for Asian populations [6-8]. Migration of people and adopting nutritional habits leads to alterations in cancer types and rates [WHO]. Diet derived compounds broadly studied for their chemopreventive activity include a wide group of polyphenols (i.e. green tea polyphenols, soy flavonoid genistein, quercetin from onions, resveratrol from grapes or curcumin), polyunsaturated fatty acids (n-3 PUFAs), carotenoids (i.e. $\beta$-carotene, lycopene or lutein), vitamins (D, E, C or folic acid) and minerals (Se, Zn, Ca) as well a dietary fiber.

\section{Diet-derived chemopreventive agents}

For many years it has been believed that diet can influence various diseases and the impact is often positive for the human organism. It was suggested already two and half thousand years ago by Hippocrates, who said "Let food be thy medicine and medicine be thy food". Diet can deliver both pro-healthy and harmful substances. Some can act as carcinogens and initiate or stimulate tumor growth. However, food includes an abundance of bioactive compounds which are beneficial to the human organism. There are data indicating a negative relationship between sufficient vegetable and fruit intake and cancer incidence. What is more, laboratory studies confirm this inverse association. It has been found that the risk of cancer incidence is half for people who eat at least five servings of fruits and vegetables per day [9]. A well-balanced diet should provide a rich source of macronutrients (omega-3 fatty acids, fiber) and micronutrients (i.e. selenium, calcium, vitamin D and E, folates) [10, 11], as well as phytochemicals (i.e. polyphenols, flavonoids, carotenoids) [4], which exert cancer preventive activities. Various ways of administration are proposed to deliver such food derived compounds in populations with normal risk of cancer. They include simple daily consumption of fruits and vegetables or functional food enriched with several phytochemicals. Food extracts can also be applied as food supplements [4, 12]. 


\section{Green tea polyphenols}

Next to water, tea is the most widely consumed beverage in the world. It was estimated that mean consumption of tea per day is around $120 \mathrm{ml}$ per person [15]. Green tea, always popular in China, Japan and India, now has gained popularity in many other countries. Black, oolong and green tea is derived from the same plant, Camellia sinensis, which is exposed to different processing methods before consumption. To obtain black tea the leaves of Camellia sinensis are fermented for a long period of time, which leads to formation of polymeric compounds, i.e. theaflavins and thearubigins. Oolong tea, often called half fermented, due to shorter fermentation time, contains polymeric as well as monomeric polyphenols. Non-fermented green tea is made from fresh tea leaves exposed to steaming and drying (to eliminate the oxidation process by inactivating the polyphenol oxidase) and contains an abundance of polyphenols naturally occurring in Camellia sinensis $[14,15]$. Green tea contains proteins (including enzymes), amino acids, carbohydrates, lipids, vitamins (B, C, E) and minerals (i.e. Ca, Mg, Cr, Fe, Zn, F, K) [13]. Green tea has been found to exert a beneficial effect on the human organism and, although results are mixed, a number of studies have revealed a correlation with a reduction of chronic disease risk, including cancer (e.g. breast, esophageal, lung, colorectal, stomach, bladder, kidney, prostate, skin, pancreatic, ovarian) [13, 16-18], cardiovascular heart disease (coronary heart disease, hypertension, atherosclerosis) [19], Parkinson disease [20], and Alzheimer disease [21]. Green tea can also promote oral health [22, 23] and bone health [24]. Consumption of this beverage is also being linked with anti-ageing processes, mainly due to its antioxidant properties $[14,15]$.

The positive health effect of green tea is mostly associated with the abundance of polyphenols, particularly flavonoids. Catechins (flavan-3-ols) make up a major group of flavonoids present in green tea leaves, including epicatechin (EC), epicatechin-3-gallate (ECG), gallocatechin (GC), epigallocatechin (EGC) and predominant (-)-epigallocatechin-3-gallate (EGCG), which constitute approximately $60 \%$ of total catechins. Widely studied medical implications are mainly attributed to epi-catechins $[14,15]$. It has been shown in animal studies that tea polyphenols, especially epigallocatechin gallate, influence several steps of carcinogenesis, including initiation, promotion and progression phases [25]. Three major mechanisms of action may benefit human health, including antioxidative, anticancer and antiangiogenic effects [14, 15, 26].

\section{Antioxidant activity}

Green tea polyphenols are responsible for significant and widely studied antioxidant properties of this beverage. Together with reactive oxygen and nitrogen species' scavenging ability, they exert beneficial effects on the human organism, protecting against harmful cigarette smoke, pollution or stress as well as cancer development [26]. It has been revealed that catechins obtained from Camellia sinensis show higher antioxidant potential than generally known antioxidants, vitamin E and C $[14,27]$. Epigallocatechin gallate (EGCG) after epicatechin gallate (ECG) is the most effective of tea catechins. Their phenolic hydroxy groups on $B$ and $D$ rings are responsible for radical scavenging properties [14, 27]. Moreover, they have the ability to chelate metal ions such as iron and copper, thus leading to decreased hydroxylic radical creation through inhibition of Fenton and Haber-Weiss reactions [13]. Besides direct antiradical influence, they can also suppress redox-sensitive transcription factors or activate antioxidant enzymes, i.e. superoxide dismutases [15].

\section{Anticancer activity}

Green tea polyphenols were shown to reduce the risk of a multitude of cancer types (see above). It is still not clear if the influence of green tea catechins on many molecular targets is attributed to their antioxidant activity or they directly and independently affect these cell signaling pathways [14]. Polyphenols from Camellia sinensis may act through stimulation of apoptosis in cancer cells, both by inactivating antiapoptotic (BCl-2, Bcl-Xl) and up-regulating pro-apoptotic (Bax, Bak, Bim, PUMA) proteins. Induced caspase- 3 and -9 activities have also been shown [16, 29, 30]. The induction of cell cycle arrest in cancer cells by EGCG and other catechins has been broadly studied. It was reported that they stimulate the expression of p21 and p27 proteins, with simultaneous inhibition of cyclin D1, cyclin-dependent kinase 2 and cyclin-dependent kinase 4, thus leading to G1 growth arrest [14, 16, 31]. Multiple signaling cascades engaged in cell survival, proliferation, differentiation and metabolism were found to be influenced by green tea polyphenol activity. Mitogen-activated protein kinases (MAPK) and Akt kinase were established as molecular targets of EGCG activity. EGCG was also shown to inhibit cancer cells' growth-promoting activity of growth factors (i.e. epidermal or insulin growth factor) [16, 31].

As migration and invasion play a crucial role in cancer metastasis to other tissues it is of high importance to stop these processes. It was reported that EGCG can affect the phase of tumor progression and it was attributed to direct or indirect inhibition of metalloproteinase (MMP) activity [16, 31, 32].

\section{Antiangiogenic activity}

Creation of new blood vessels from pre-existing ones inside a tumor, called angiogenesis, promotes cancer development through its nourishment and oxygenation. Besides inhibiting activity of metalloproteinases which are involved in angiogenesis, EGCG was revealed to affect vascular endothelial growth factor (VEGF) binding ability to its receptor. VEGF is closely related to tumor-induced angiogenesis, acting as a mitogen factor for endothelial cells [16, 31, 33]. An independent study also revealed the ability of EGCG and green tea extract to inhibit the secretion of VEGF protein [34].

\section{Polyunsaturated fatty acids (PUFAs)}

A multitude of epidemiological studies have indicated an association between polyunsaturated fatty acid consumption and cancer risk, especially breast, prostate and colon cancer [35-37]. A protective effect of the long-chain PUFAs is also revealed by in vitro and animal studies [38-41]. The ratio of consumed $n-6$ to $n-3$ polyunsaturated fatty acids seems to play the major role in cancer development [42]. They are not synthesized in humans (essential fatty acids), so they must 
be supplemented with diet. The metabolic precursors of n-3 PUFAs [i.e. eicosapentaenoic acid (EPA), docosahexaenoic acid (DHA) and n-6 PUFAs (i.e. arachidonic acid (AA), $\gamma$-linolenic acid (GLA)], are respectively $\alpha$-linolenic acid (ALA, $n-3$ ) and linoleic acid (LA, n-6) [43]. Linoleic acid is found in large amounts in sunflower, soy and corn oils, while ALA is present in linseed and rapeseed oils. Long-chain fatty acids $\mathrm{n}-3$ can be found in cold-water fish, including herring, halibut, salmon, mackerel and tuna, or warm-water fish like cod $[7,43,44]$. Since the same enzymes are engaged in LA and ALA conversion to subsequent polyunsaturated PUFAs, diet may have an important influence on types of fatty acids present in the body. However, reactions of interconversion to some $n-3$ fatty acids (i.e. DHA) are very inefficient; thus supplementation of the diet with these fatty acids seems to be the most efficient way to elevate their concentrations in plasma and tissue [45].

Although diet rich in dietary fat is often linked with increased risk of cancer, especially hormone-dependent cancer incidence, the types of consumed fatty acids have a significant impact. A preventive effect of $n-3$ PUFAs and cancer stimulating effect of $n-6$ PUFAs is suggested [45]. Nowadays, Western diets are rich in n-6 PUFAs due to high plant oil intake and industrial meat production from animals fed with grains containing $n-6$ fatty acids. The ratio of $n-6$ to $\mathrm{n}-3$ fatty acids has increased and is in the range 15-20:1, while it should be 4-5:1 [46, WHO]. Changing dietary patterns in populations originally consuming large amounts of n-3 PUFAs, e.g. Japanese, may be responsible for elevated breast cancer incidence [7].

\section{Chemopreventive activity of n-3 PUFAs}

Dietary PUFAs exert a suppressing (n-3) or promoting (n-6) effect on cancer mainly through their derivatives, eicosanoids, hormone-like lipids. Prostaglandins (PG), thromboxanes (TX) and leukotrienes (LT) are synthesized in enzymatic reactions with use of cyclooxygenases (COX) and lipoxygenases (LOX). The n-3 and n- 6 long chain fatty acids compete for the enzymes and eicosanoids derived from them reveal opposing effects on cell proliferation, differentiation, angiogenesis, metastasis and inflammatory responses [32, 45]. The first step of eicosanoid production is the hydrolytic release of PUFA from the cell membrane. Since arachidonic acid (AA, $n-6)$ is the most abundant PUFA among phospholipids in cell membranes, pro-inflammatory and cancer promoting eicosanoids are mainly produced. Diet enrichment with n-3 PUFAs may silence the effect of AA-derived eicosanoids through replacement of AA in membranes, thus increasing the amount of precursors for biosynthesis of cancer suppressing prostaglandins and leukotrienes [47]. Moreover, high consumption of $n-3$ long chain fatty acids leads to decreased production of $A A$ from $L A$, due to stronger affinity of $n-3$ than $\mathrm{n}-6$ PUFAs to enzymes involved in this process $[42,43]$.

It was revealed that PUFAs and their derivatives may influence several molecular signaling pathways involved in basic processes including cell growth, differentiation, apoptosis or metastasis. The n-3 PUFAs were found to down regulate protein kinase $C$ and ras [48, 49], ERK1/2 [50], NFKB [51] and COX-2 [52]. Activation of PPAR- $\gamma$ receptor by DHA was shown to stimulate cell apoptosis [53]. Animal and human studies demonstrated the protective effect of EPA and DHA against free radicals and reactive oxygen species formation $[42,54,55]$.

\section{Glucosinolates/isothiocyanates}

Crucifers (the plant family Cruciferae, also known as Brassicaceae) include several widely consumed vegetables, e.g. cabbage, broccoli, cauliflower, parsnip, Brussels sprouts, radish, horseradish, turnip and kale [56]. Epidemiological data suggest an inverse association between cruciferous vegetables intake and risk of many cancers, e.g. lung, breast, stomach, pancreas, prostate, bladder, thyroid, skin and colon cancer. Significantly, this correlation was found to be more prominent than the general effect linked to vegetable and fruit consumption $[56,57]$. Despite the variety of bioactive compounds present in crucifers, i.e. polyphenols, minerals and vitamins, a superior role in cancer prevention is ascribed to glucosinolates and their decomposition products, isothiocyanates [58]. Glucosinolates (GS) characterized to date are a welldefined group of chemical compounds consisting of three basic structures including a $\beta$-D-thioglucose group, sulfonated oxime group and side chain derived from one of the protein amino acids [59]. Due to the acidic nature of sulfate groups, in plants glucosinolates are accumulated as potassium salts sequestered to vacuoles and probably protect against herbivores and microbes [60]. Glucosinolates are highly stable and when consumed cannot act as bioactive compounds until subjected to enzymatic hydrolysis due to myrosinase action. This $\beta$-thioglucosidase is released from myrosin cells when crucifers are subjected to cutting or mastication and catalyze hydrolysis of the glycoside bond [61]. Glucosinolates commonly found in cruciferous vegetables include gluconasturtiin, sinigrin, glucoraphanin and glucobrassicin, which are hydrolyzed, resulting in creation of phenyl isothiocyanate, allyl isothiocyanate, sulforaphane and indole-3-carbinol, respectively [58]. The overall content and form of GS within plants are strongly affected by environmental conditions such as location, soil conditions and time of harvest. Importantly, the total amount of glucosinolates varies due to conditions of processing and domestic cooking, considering thermal degradation and washout occurrence $[56,59]$.

Several mechanisms of cancer protection by glucosinolates/isothiocyanates have been proposed. The most studied is the influence of the compounds on detoxification pathways leading to increased activity of phase I and phase II enzymes and resulting in lowered amounts of carcinogens within the body due to their decreased formation as well as increased excretion. Moreover, altered activity of the enzymes was reported in vitro and in vivo [62]. Glucosinolates/isothiocyanates were also shown to decrease cancerous cell proliferation and regulate numerous proteins engaged in apoptosis control, i.e. caspases, p53, cyclin-dependent kinases, and pro-apoptotic members of the Bcl-2 protein family, or affect tubulin polymerization, thus leading to cell apoptosis [58]. Furthermore, some of the GS derivatives were reported to decrease expression of mandatory cyclins and cell cycle inhibitors, thus dysregulating the cell cycle leading to $G_{1} S$ or $G_{2} M$ arrest depending on cell type [63]. What 
is more, some of the isothiocyanates were revealed to affect estrogen metabolism, resulting in decreased incidence of hormone-dependent cancers. The effect is attributed both to increased estrogen metabolism resulting in its lowered concentration in the blood [64] and altered estrogen receptor (ER) activity due to inhibited transcription of ER-coding genes or its degradation [65].

\section{Carotenoids}

Among other phytochemicals present in food, carotenoids constitute a wide group of approximately 600 compounds found in almost all colored vegetables, while around 40 of them are present in daily diet. However, only 21 carotenoids are found in human serum/plasma due to differences in their bioavailability and absorption in the gut. The most commonly studied are lycopene (watermelon, tomatoes - well absorbed from tomato juice and sauce, red grapefruit, briar), $\beta$-carotene (carrots, leafy greens), lutein (dihydroxy form of $\alpha$-carotene, present in kale, spinach, mango, and oranges) and zeaxanthin (dihydroxy form of $\beta$-carotene, present in corn). Since high consumption of fruits and vegetables is associated with decreased cancer risk, carotenoids are being extensively investigated for anticarcinogenic activity [66-68].

At first, the cancer preventing effects were linked mainly to the precursors of vitamin A, then non-provitamin A carotenoids were also found to act as anticarcinogens [69]. They exert growth inhibitory activity in a wide group of cancer cells, including colon, prostate, breast and lung tumor cells [70]. Carotenoids were found to be modulators of many signaling pathways, engaged in cell proliferation and apoptosis. Akt and MAPK kinase activity was revealed to be impaired in the presence of carotenoids. They can also play a role as stimulators of apoptosis by activation of caspase cascades and by altering the status of $\mathrm{Bcl}-2$ proteins $[69,71]$. Carotenoids may influence the cell cycle of cancer cells, thus leading to their growth inhibition. Lycopene was found to stop cell cycle progression in $G_{0} / G_{1}[72]$ or $G_{1} / S$ [73] dependently on cancer cell type. Additionally, the levels of p53 protein are altered in cells treated with carotenoids [69]. Lycopene has also been found to suppress IGF-I stimulated growth of cancer cells by preventing the binding of this growth factor to its receptor $[2,74]$. COX-2 activity was revealed to be decreased in colon cancer cells exposed to $\beta$-carotene [75]. Moreover, lycopene was found to enhance gap junction communication through up-regulation of connexin- 43 in breast cancer cells, which can lead to the improvement of cell differentiation [76].

\section{Vitamins and minerals}

Intake of minerals and vitamins in daily diet is essential for health maintenance. Although they are present in trace amounts within tissues, they play a significant role in a variety of biological processes. Some of them also have a positive impact on the process of carcinogenesis. Anticancer activity of vitamins $E$ and $C$ was observed, mostly due to their antioxidant effects. The protective influence of vitamin $C$ is revealed in relation to e.g. gastric cancer through inhibiting formation of $\mathrm{N}$-nitroso compounds. Besides the reactive oxygen species moderating effect, vitamin E may also induce can- cer cell differentiation and apoptosis. Vitamin D and folic acid were also observed to have an impact on carcinogenesis [3].

\section{Vitamin D}

Vitamin D is a fat-soluble prohormone naturally occurring in very small amounts in food. Two forms of this vitamin can be distinguished: calciferol $\left(D_{2}\right)$ and cholecalciferol $\left(D_{3}\right)$, which is produced in skin after exposure to UV-B light. Active forms of vitamin $D$ are obtained in the body after their conversion in the liver to calcidiol (25-hydroxyvitamin D) and in kidneys to calcitriol (1, 25-dihydroxyvitamin D) [77]. It has been revealed that human cells, both normal and cancer cells, demonstrate specific receptors (VDR) for vitamin D metabolites, thus being susceptible to their activity [78]. Vitamin D action has been attributed to the regulation of multiple genes (more than 60) engaged in cell proliferation, differentiation, apoptosis and angiogenesis [79-84]. Biological activity of calcitriol is exerted when it binds to VDR receptors, which leads to formation of a heterodimer with retinoid $X$ receptor and expression of specific genes containing vitamin $D$ response element [85]. The inhibition of cell proliferation and metastasis as well as stimulation of cell differentiation is observed as an effect of vitamin D action $[77,86]$. This activity of calcitriol is linked to decreased risk of prostate and colon cancer risk. Moreover, it was noted that sunlight exposure was inversely associated with cancer incidence [87].

\section{Folate}

Folic acid (also known as vitamin $\mathrm{B}_{9}$ ) is a constituent found in large amounts in green leafy vegetables and fresh fruits. It plays a crucial role in proper cell division and growth and takes part in nucleotide biosynthesis [10]. Its cancer preventive effects are mainly attributed to the delivery of methyl groups for DNA synthesis and gene expression, thus protecting against DNA damage. It was suggested that insufficient folic acid consumption may trigger loss of DNA integrity through misincorporation of uracil to the chain of DNA and induces breaks in chromosomes. Reversion of these defects was shown after folate supplementation [88, 89]. A reverse association was observed between folic acid intake and colon and breast cancer incidence. Animals fed with a diet poor in folate were more likely to suffer from colorectal cancer. A number of epidemiological studies revealed 25-35\% reduction in colon cancer incidence when comparing the groups with the highest and lowest folate intake $[3,10]$. Decreased risk of colorectal cancer by approximately $75 \%$ was noted in women taking high-folate multivitamins for more than 15 years [10, 90].

\section{Selenium}

A variety of in vitro, animal and epidemiological studies suggest a preventive role of selenium against human cancer development, especially tumors of the gastrointestinal tract. Low levels of selenium in serum were associated with increased risk of prostate cancer. It is suggested that selenium may inhibit initiation and promotion phases of carcinogenesis [10]. Besides its antioxidant effect on lipid peroxidation, it can alter the process of DNA adduct formation. 
It blocks formation of carcinogens and their binding to DNA. Selenium may also reduce cancer progression through improving the immune response in the organism, e.g. by stimulation of cytotoxic activity of natural killer cells [91]. Several studies have revealed selenium-induced apoptosis in tumor cells [92] as well as inhibition of cell proliferation involving alternations in MAPK kinases and Akt kinase signaling pathways [93]. It was also proposed that it could act as a chemopreventive agent by decreasing angiogenesis within the tumor [94-96]. What is interesting, small amounts of Se added to a diet deficient in this micronutrient results in improved activity of selenoproteins and detoxification enzymes of phase I and II as well as ameliorated function of the immune system, whereas supranutritional intake of selenium leads to cancer prevention through the above-described influence on the cell cycle, apoptosis and angiogenesis $[58,97]$.

\section{Calcium}

Calcium constitutes an essential macroelement for human health. Dairy products (milk, yogurts, and cheese), dark green vegetables, legumes and nuts constitute a good source of this micronutrient. Although some results are inconsistent, a number of epidemiological studies have attributed calcium intake with decreased colon adenoma and cancer $[90,98]$. The mechanism underlying this protective effect is mainly due to binding and inactivating the pro-cancerogenic activity of bile acids on colon epithelial cells. In addition, calcium was found to inhibit epithelial cell proliferation or induce their differentiation through altering cell signaling pathways $[86,87,99,100]$.

\section{Conclusion}

Based on various studies outlined in this review reporting a broad spectrum of naturally occurring compounds with chemopreventive activity, intense consideration of them as potential therapeutics is quite intelligible. Some of these may be already found as extracts or pure substances available for daily supplementation and are becoming a common dietary habit. However, providing a well-balanced diet containing an abundance of biologically active compounds should become a daily habit.

The authors declare no conflict of interest.

\section{References}

1. Sporn MB, Dunlop NM, Newton DL, Smith JM. Prevention of chemical carcinogenesis by vitamin $A$ and its synthetic analogs (retinoids). Fed Proc 1976; 35: 1332-8.

2. Kucuk O. Cancer chemoprevention. Cancer Metastasis Rev 2002; 21: 189-97.

3. Greenwald P, Milner JA, Anderson DE, McDonald SS. Micronutrients in cancer chemoprevention. Cancer Metastasis Rev 2002; 21: 217-30.

4. Mehta RG, Murillo G, Naithani R, Peng X. Cancer chemoprevention by natural products: how far have we come? Pharm Res 2010; 27 : 950-61.

5. Chen C, Kong AN. Dietary cancer-chemopreventive compounds: from signaling and gene expression to pharmacological effects. Trends Pharmacol Sci 2005; 26: 318-26.
6. Kurahashi N, Iwasaki M, Sasazuki S, Otani T, Inoue M, Tsugane S. Soy product and isoflavone consumption in relation to prostate cancer in Japanese men. Cancer Epidemiol Biomarkers Prev 2007; 16: 538-45.

7. Rose DP. Dietary fatty acids and cancer. Am J Clin Nutr 1997; 66 (4 Suppl): 998S-1003S.

8. Dorai T, Aggarwal BB. Role of chemopreventive agents in cancer therapy. Cancer Lett 2004; 215: 129-40.

9. Surh YJ. Cancer chemoprevention with dietary phytochemicals. Nat Rev Cancer 2003; 3: 768-80.

10. Vaisman N, Arber N. The role of nutrition and chemoprevention in colorectal cancer: observation to expectations. Best Pract Res Clin Gastroenterol 2002; 16: 201-17.

11. Johnson IT. New approaches to the role of diet in the prevention of cancers of the alimentary tract. Mutat Res 2004; 551: 9-28.

12. Kelloff GJ, Crowell JA, Steele VE, et al. Progress in cancer chemoprevention: development of diet-derived chemopreventive agents. J Nutr 2000; 130: 467S-71S.

13. McKay DL, Blumberg JB. The role of tea in human health: an update. I Am Coll Nutr 2002; 21: 1-13.

14. Zaveri NT. Green tea and its polyphenolic catechins: medicinal uses in cancer and noncancer applications. Life Sci 2006; 78: 2073-80.

15. Cabrera C, Artacho R, Giménez R. Beneficial effects of green tea a review. J Am Coll Nutr 2006; 25: 79-99.

16. Shankar S, Ganapathy S, Srivastava RK. Green tea polyphenols: biology and therapeutic implications in cancer. Front Biosci 2007; 12: 4881-99.

17. Mukhtar H, Ahmad N. Tea polyphenols: prevention of cancer and optimizing health. Am J Clin Nutr 2000; 71: 1698S-702S (discussion 1703S-4S).

18. Yang CS, Maliakal P, Meng X. Inhibition of carcinogenesis by tea. Ann Rev Pharmacol Toxicol 2002; 42: 25-54.

19. Nakachi K, Matsuyama S, Miyake S, Suganuma M, Imai K. Preventive effects of drinking green tea on cancer and cardiovascular disease: epidemiological evidence for multiple targeting prevention. Biofactors 2000; 13: 49-54.

20. Pan T, Jankovic J, Le W. Potential therapeutic properties of green tea polyphenols in Parkinson's disease. Drugs Aging 2003; 20: 711-21.

21. Choi YT, Jung CH, Lee SR, et al. The green tea polyphenol (-)epigallocatechin gallate attenuates beta amyloid-induced neurotoxicity in cultured hippocampal neurons. Life Sci 2001; 70: 603-14.

22. Stapleton PD, Shah S, Anderson JC, Hara Y, Hamilton-Miller JM, Taylor PW. Modulation of beta-lactam resistance in Staphylococcus aureus by catechins and gallates. Int J Antimicrob Agents 2004; 23: 462-7.

23. Rasheed A, Haider M. Antibacterial activity of Camellia sinensis extracts against dental caries. Arch Pharm Res 1998; 21: 348-52.

24. Hegarty VM, May HM, Khaw KT. Tea drinking and bone mineral density in older women. Am J Clin Nutr 2000; 71: 1003-7.

25. Chung FL, Schwartz J, Herzog CR, Yang YM. Tea and cancer prevention: studies in animals and humans. J Nutr 2003; 133: 3268S-74S.

26. Cooper R, Morré DJ, Morré DM. Medicinal benefits of green tea. Part II. Review of anticancer properties. J Altern Complement Med 2005; 11: 639-52.

27. Rice-Evans CA, Miller NJ, Bolwell PG, Bramley PM, Pridham JB. The relative antioxidant activities of plant-derived polyphenolic flavonoids. Free Radic Res 1995; 22: 375-83.

28. Salah N, Miller NJ, Paganga G, Tijburg L, Bolwell GP, Rice-Evans C. Polyphenolic flavanols as scavengers of aqueous phase radicals and as chain-breaking antioxidants. Arch Biochem Biophys 1995; 322: $339-46$

29. Qin J, Xie LP, Zheng XY, Wang YB, Bai Y, Shen HF, Li LC, Dahiya R. A component of green tea, (-)-epigallocatechin-3-gallate, promotes apoptosis in T24 human bladder cancer cells via modulation of the PI3K/Akt pathway and Bcl-2 family proteins. Biochem Biophys Res Commun 2007; 354: 852-7.

30. Chen C, Shen G, Hebbar V, Hu R, Owuor ED, Kong AN. Epigallocatechin-3-gallate-induced stress signals in HT-29 human colon adenocarcinoma cells. Carcinogenesis 2003; 24: 1369-78.

31. Khan N, Afaq F, Saleem M, Ahmad N, Mukhtar H. Targeting multiple signaling pathways by green tea polyphenol (-)-epigallocatechin-3-gallate. Cancer Res 2006; 66: 2500-5. 
32. Annabi B, Lachambre MP, Bousquet-Gagnon N, Page M, Gingras D, Beliveau R. Green tea polyphenol (3)-epigallocatechin 3-gallate inhibits MMP-2 secretion and MT1-MMP-driven migration in glioblastoma cells. Biochim Biophys Acta 2002; 1542: 209-20.

33. Tang FY, Nguyen N, Meydani M. Green tea catechins inhibit VEGFinduced angiogenesis in vitro through suppression of VE-cadherin phosphorylation and inactivation of Akt molecule. Int J Cancer 2003 106: 871-8.

34. Sartippour MR, Shao ZM, Heber D, et al. Green tea inhibits vascular endothelial growth factor (VEGF) induction in human breast cancer cells. J Nutr 2002; 132: 2307-11.

35. Terry PD, Rohan TE, Wolk A. Intakes of fish and marine fatty acids and the risks of cancers of the breast and prostate and of other hormone related cancers: a review of the epidemiologic evidence. Am Clin Nutr 2003; 77: 532-43.

36. Hall MN, Chavarro JE, Lee IM, Willett WC, Ma J. A 22-year prospective study of fish, n-3 fatty acid intake, and colorectal cancer risk in men. Cancer Epidemiol Biomarkers Prev 2008; 17: 1136-43.

37. Theodoratou E, McNeill G, Cetnarskyj R, et al. Dietary fatty acids and colorectal cancer: a case-control study. Am J Epidemiol 2007; 166 181-95.

38. Boudreau MD, Sohn KH, Rhee SH, Lee SW, Hunt JD, Hwang DH. Suppression of tumor cell growth both in nude mice and in culture by n-3 polyunsaturated fatty acids: mediation through cyclooxygenase independent pathways. Cancer Res 2001; 61: 1386-91.

39. Narayanan BA, Narayanan NK, Reddy BS. Docosahexaenoic acid regulated genes and transcription factors inducing apoptosis in human colon cancer cells. Int J Oncol 2001; 19: 1255-62.

40. Bartsch H, Nair J, Owen RW. Dietary polyunsaturated fatty acids and cancers of the breast and colorectum: emerging evidence for their role as risk modifiers. Carcinogenesis 1999; 20: 2209-18.

41. Calviello G, Di Nicuolo F, Gragnoli S, et al. n-3 PUFAs reduce VEGF expression in human colon cancer cells modulating the COX-2/PGE2 induced ERK-1 and -2 and HIF-1-a induction pathway. Carcinogenesis 2004; 25: 2303-10.

42. Larsson SC, Kumlin M, Ingelman-Sundberg M, Wolk A. Dietary longchain n-3 fatty acids for the prevention of cancer: a review of poten tial mechanisms. Am J Clin Nutr 2004; 79: 935-45.

43. Rose DP, Connolly JM. Omega-3 fatty acids as cancer chemopreventive agents. Pharmacol Ther 1999; 83: 217-44

44. Meyer BJ, Mann NJ, Lewis JL, Milligan GC, Sinclair AJ, Howe PR. Dietary intakes and food sources of omega- 6 and omega-3 polyunsaturated fatty acids. Lipids 2003; 38: 391-8.

45. Berquin IM, Edwards IJ, Chen YQ. Multi-targeted therapy of cancer by omega-3 fatty acids. Cancer Lett 2008; 269: 363-77.

46. Simopoulos AP. The omega-6/omega-3 fatty acid ratio, genetic variation, and cardiovascular disease. Asia Pac J Clin Nutr 2008; 17 131-4.

47. Crawford M, Galli C, Visioli F, Renaud S, Simopoulos AP, Spector AA. Role of plant-derived omega-3 fatty acids in human nutrition. Ann Nutr Metab 2000; 44: 263-5.

48. Reddy BS, Simi B, Patel N, Aliaga C, Rao CV. Effect of amount and types of dietary fat on intestinal bacterial 7 alpha-dehydroxylase and phosphatidylinositol-specific phospholipase $C$ and colonic mucosal diacylglycerol kinase and PKC activities during stages of colon tumor promotion. Cancer Res 1996; 56: 2314-20.

49. Chang WL, Chapkin RS, Lupton JR. Fish oil blocks azoxymethaneinduced rat colon tumorigenesis by increasing cell differentiation and apoptosis rather than decreasing cell proliferation. J Nutr 1998; 128: 491-7.

50. Sauer LA, Blask DE, Dauchy RT. Dietary factors and growth and metab olism in experimental tumors. J Nutr Biochem 2007; 18: 637-49.

51. Novak TE, Babcock TA, Jho DH, Helton WS, Espat NJ. NF-kappa B inhibition by omega-3 fatty acids modulates LPS-stimulated macrophage TNF-alpha transcription. Am J Physiol Lung Cell Mol Physiol 2003; 284: L84-9.

52. Badawi AF, El-Sohemy A, Stephen LL, Ghoshal AK, Archer MC. The effect of dietary n-3 and n-6 polyunsaturated fatty acids on the expression of cyclooxygenase 1 and 2 and levels of p21ras in rat mammary glands. Carcinogenesis 1998; 19: 905-10.

53. Zand H, Rhimipour A, Bakhshayesh M, Shafiee M, Nour Mohammadi I, Salimi S. Involvement of PPAR-gamma and p53 in DHA induced apoptosis in Reh cells. Mol Cell Biochem 2007; 304: 71-7.
54. Takahashi M, Tsuboyama-Kasaoka N, Nakatani T, Ishii M, Tsutsumi S, Aburatani $\mathrm{H}$, Ezaki O. Fish oil feeding alters liver gene expressions to defend against PPARalpha activation and ROS production. Am J Physiol Gastrointest Liver Physiol 2002; 282: G338-48.

55. Calder PC, Grimble RF. Polyunsaturated fatty acids, inflammation and immunity. Eur J Clin Nutr 2002; 56: S14-9.

56. Keck AS, Finley JW. Cruciferous vegetables: cancer protective mechanisms of glucosinolate hydrolysis products and selenium. Integr Cancer Ther 2004; 3: 5-12.

57. Verhoeven DT, Goldbohm RA, van Poppel G, Verhagen H, van den Brandt PA. Epidemiological studies on brassica vegetables and cancer risk. Cancer Epidemiol Biomarkers Prev 1996; 5: 733-48.

58. Finley JW. Proposed criteria for assessing the efficacy of cancer reduction by plant foods enriched in carotenoids, glucosinolates, polyphenols and selenocompounds. Ann Bot 2005; 95: 1075-96.

59. Moreno DA, Carvajal M, López-Berenguer C, García-Viguera C. Chemical and biological characterisation of nutraceutical compounds of broccoli. J Pharm Biomed Anal 2006; 41: 1508-22.

60. Fenwick GR, Heaney RK, Mullin WJ. Glucosinolates and their breakdown products in food and food plants. Crit Rev Food Sci Nutr 1983; 18: 123-201.

61. Grubb CD, Abel S. Glucosinolate metabolism and its control. Trends Plant Sci 2006; 11: 89-100.

62. Hecht SS. Chemoprevention of cancer by isothiocyanates, modifiers of carcinogen metabolism. J Nutr 1999; 129: 768S-74S.

63. Keum YS, Jeong WS, Kong AN. Chemoprevention by isothiocyanates and their underlying molecular signaling mechanisms. Mutat Res 2004; 555: 191-202.

64. Rahman KW, Li Y, Wang Z, Sarkar SH, Sarkar FH. Gene expression profiling revealed survivin as a target of 3, 3'-diindolylmethaneinduced cell growth inhibition and apoptosis in breast cancer cells. Cancer Res 2006; 66: 4952-60.

65. Meng O, Yuan F, Goldberg ID, Rosen EM, Auborn K, Fan S. Indole3 -carbinol is a negative regulator of estrogen receptor- $\alpha$ signaling in human tumor cells. J Nutr 2000; 130: 2927-31.

66. Nishino H, Murakosh M, li T, et al. Carotenoids in cancer chemoprevention. Cancer Metastasis Rev 2002; 21: 257-64.

67. Khachik F, Beecher GR, Smith JC Jr. Lutein, lycopene, and their oxidative metabolites in chemoprevention of cancer. J Cell Biochem 2004; 59: 236-46.

68. Palozza P, Simone RE, Catalano A, Mele MC. Tomato lycopene and lung cancer prevention: from experimental to human studies. Cancers 2011; 3: 2333-57.

69. Landrum JT. Carotenoids: physical, chemical, and biological functions and properties. CRC Press Sci 2009; 437-65.

70. Palozza P, Serini S, Calviello G. Carotenoids as modulators of intracellular signaling pathways. Curr Signal Transduct Ther 2006; 1: 325-35.

71. Palozza P, Sheriff A, Serini S, Boninsegna A, Maggiano N, Ranelletti FO, Calviello G, Cittadini A. Lycopene induces apoptosis in immortalized fibroblasts exposed to tobacco smoke condensate through arresting cell cycle and down-regulating cyclin D1 pAKT and pBad. Apoptosis 2005; 10: 1445-56.

72. Palozza P, Serini S, Boninsegna A, Bellovino D, Lucarini M, Monastra G, Gaetani S. The growth-inhibitory effects of tomatoes digested in vitro in colon adenocarcinoma cells occur through down regulation of cyclin D1, Bcl-2 and Bcl-xL. Br J Nutr 2007; 98: 789-95.

73. Ivanov NI, Cowell SP, Brown P, Rennie PS, Guns ES, Cox ME. Lycopene differentially induces quiescence and apoptosis in androgenresponsive and -independent prostate cancer cell lines. Clin Nutr 2007; 26: 252-63.

74. Nahum A, Zeller L, Danilenko M, Prall OW, Watts CK, Sutherland RL, Levy J, Sharoni Y. Lycopene inhibition of IGF-induced cancer cell growth depends on the level of cyclin D1. Eur J Nutr 2006; 45: 275-82.

75. Palozza P, Serini S, Maggiano N, Tringali G, Navarra P, Ranelletti FO, Calviello G. $\beta$-Carotene downregulates the steady-state and heregulin- $\alpha$-induced COX-2 pathways in colon cancer cells. J Nutr 2005; 135: 129-36.

76. Chalabi N, Delort L, Satih S, Déchelotte P, Bignon YJ, Bernard-GalIon DJ. Immunohistochemical expression of RAR $\alpha, R A R \beta$, and $C \times 43$ in breast tumor cell lines after treatment with lycopene and correlation with RT-QPCR. J Histochem Cytochem 2007; 55: 877-83. 
77. Ali MM, Vaidya V. Vitamin D and cancer. J Cancer Res Ther 2007 ; 3: 225-30.

78. Holick MF. Vitamin D deficiency. N Engl J Med 2007; 357: 266-81.

79. Holick MF. Evolution and function of vitamin D. Recent Results Cancer Res 2003; 164: 3-28.

80. DeLuca HF. Overview of general physiologic features and functions of vitamin D. Am J Clin Nutr 2004; 80: 1689S-96S.

81. Moffatt KA, Johannes WU, Hedlund TE, Miller GJ. Growth inhibitory effects of 1alpha, 25-dihydroxyvitamin D3 are mediated by increased levels of p21 in the prostatic carcinoma cell line ALVA-31. Cancer Res 2001; 61: 7122-9.

82. Sutton AL, Zhang X, Ellison TI, Macdonald PN. The 1,25(OH)2D3-regulated transcription factor MN1 stimulated vitamin D receptormediated transcription and inhibits osteoblastic cell proliferation. Mol Endocrinol 2005; 19: 2234-44

83. Lu J, Goldstein KM, Chen P, Huang S, Gelbert LM, Nagpal S. Tran scriptional profiling of keratinocytes reveals a vitamin D-regulated epidermal differentiation network. J Invest Dermatol 2005; 124: 778-85.

84. Wagner N, Wagner KD, Schley G, Badiali L, Theres H, Scholz H. 1,25 dihydroxyvitamin D3-induced apoptosis of retinoblastoma cells is associated with reciprocal changes of $\mathrm{Bcl}-2$ and bax. Exp Eye Res 2003; 77: 1-9.

85. Davis CD. Vitamin D and cancer: current dilemmas and future research needs. Am J Clin Nutr 2008; 88: 565S-9S.

86. Fedirko V, Bostick RM, Flanders WD, et al. Effects of vitamin D and calcium on proliferation and differentiation in normal colon mucosa: a randomized clinical trial. Cancer Epidemiol Biomarkers Prev 2009; 18: 2933-41

87. Lamprecht SA, Lipkin M. Cellular mechanisms of calcium and vitamin D in the inhibition of colorectal carcinogenesis. Ann N Y Acad Sci 2001; 952: 73-87.

88. Choi SW, Mason JB. Folate and carcinogenesis: an integrated scheme. J Nutr 2000; 130: 129-32.

89. Blount BC, Mack MM, Wehr CM, et al. Folate deficiency causes uracil misincorporation into human DNA and chromosome breakage: implications for cancer and neuronal damage. Proc Natl Acad Sci U S A 1997; 94: 3290-5.

90. Hawk ET, Umar A, Viner JL. Colorectal cancer chemoprevention an overview of the science. Gastroenterology 2004; 126: 1423-47.

91. Whanger PD. Selenium and its relationship to cancer: an update. Br J Nutr 2004; 91: 11-28.

92. Ip C, Dong Y. Methylselenocysteine modulates proliferation and apoptosis biomarkers in premalignant lesions of the rat mammary gland. Anticancer Res 2001; 21: 863-7.

93. Wang Z, Jiang C, Ganther H, Lü J. Antimitogenic and proapoptotic activities of methylseleninic acid in vascular endothelial cells and associated effects on PI3K-AKT, ERK, JNK and P38 MAPK signaling. Cancer Res 2001; 61: 7171-8.

94. Lu J. Apoptosis and angiogenesis in cancer prevention by selenium Adv Exp Med Biol 2001; 492: 131-45.

95. Davis CD, Finley JW. Chemical versus food forms of selenium in cancer prevention. In: Functional foods and nutraceuticals in cancer pre vention. Watson RR (ed.). Iowa State Press, Ames, IA 2003; 55-86.

96. Lu J, Jiang C. Antiangiogenic activity of selenium in cancer chemoprevention: metabolite-specific effects. Nutr Cancer 2001; 40: 64-73.

97. Fimognari C, Nüsse M, lori R, Cantelli-Forti G, Hrelia P. The new isoth iocyanate 4-(methylthio)butylisothiocyanate selectively affects cell-cycle progression and apoptosis induction of human leukemia cells. Invest New Drugs 2004; 22: 119-29.

98. Park SY, Murphy SP, Wilkens LR, Nomura AM, Henderson BE, Kolonel LN. Calcium and vitamin D intake and risk of colorectal cancer: the Multiethnic Cohort Study. Am J Epidemiol 2007; 165: 784-93.

99. Milner JA, McDonald SS, Anderson DE, Greenwald P. Molecular targets for nutrients involved with cancer prevention. Nutr Cancer 2001; 41: 1-16.

100. Holt PR, Wolper C, Moss SF, Yang K, Lipkin M. Comparison of calcium supplementation or low-fat dairy foods on epithelial cell proliferation and differentiation. Nutr Cancer 2001; 41: 150-5.

\section{Address for correspondence}

\section{Ewa Langner}

Department of Medical Biology

Institute of Agricultural Medicine Jaczewskiego 2

20-950 Lublin

e-mail: ewa.langner@gmail.com

Submitted: $\quad 6.04 .2011$

Accepted: $\quad 9.08 .2011$ 